\title{
A THEORETICAL MODEL TO SOLVE COST SHIFTING PROBLEM
}

\author{
Rafiuddin Ahmed ${ }^{1}$ \\ Chris Leggett ${ }^{2}$ \\ Khondaker Mizahur Rahman ${ }^{3}$ \\ ${ }^{1}$ School of Business, James Cook University, Douglas, Queensland, Australia \\ ${ }^{2}$ School of Business, James Cook University, Douglas, Queensland, Australia \\ ${ }^{3}$ Professor, School of Business, Nanzan University, Nagoya, Japan
}

\begin{abstract}
Cost shifting strategy in service organizations causes difficulties between co-existing internal business units each competing for scarce resources. Within regulatory and legal constraints, cost shifting between business units instigates concomitant changes to each unit's profitability/budget-surpluses. For internal monopoly and competitive units, this strategy has shortcomings. Through management sponsored training programs, employee learning and productivity improvements offer a long-term approach to better address this short-term cost shifting problem. We mathematically model this solution, and outline further research that builds on this long-term cost shifting approach.
\end{abstract}

Keywords: Cost shifting, reduction, competitive, learning, monopoly, long term, productivity

\section{INTRODUCTION}

The practice of cost shifting in service organizations remains a contentious issue in a number of disciplines, including cost accounting, management accounting, and regulatory economics (Breautigan and Panzer 1990, Brennan 1990, EBRI 1993, Gal-Or 1993, McGowan and Vendrzyk 2002). Literature demonstrates cost shifting practices primarily involve of overheads such as those imposed or allocated by senior management, but this practice excludes costs incurred within a service department or business segment (Breautigan and Panzer 1990, Brennan 1990, Rogerson 1992, EBRI 1993, Gal-Or 1993, Cavalluzzo et al. 1998, McGowan and Vendrzyk 2002).

Cost shifting is an organizational strategy rather than a policy (EBRI 1993). It helps to achieve organizational goals such as: achieving profit targets, maintaining market share, and/or providing planning and control directions (Rogerson 1992, Cavalluzzo et al. 1998). In USA defense industry, cost shifting between organizational units is used as a return on investment strategy (Rogerson 1992). Here, defense product buyers purchasing from monopoly units via sole supply contracts pursue increased product profitability by on-selling to other customers - often in non-strategic semi-competitive segments (Braeutigam and Panzar 1989, Breautigan and Panzer 1990, EBRI 1993, Cavalluzzo et al. 1998, McGowan and Vendrzyk 2002). Similar cost shifting practices arise in US public hospitals, and in other public utilities (Braeutigam and Panzar 1989, Breautigan and Panzer 1990, Brennan 1990, EBRI 1993). 
Cost shifting offers short-term temporary organizational unit fixes - often at the expense of another internal business unit (EBRI 1993, Gal-Or 1993, Cavalluzzo et al. 1998, McGowan and Vendrzyk 2002). Over longer time periods such resultant expenditure shifts and/or productivity cost shifts have received little academic attention (Gal-Or 1993, Cavalluzzo et al. 1998). Hence, this service organization study addresses the longer-term effects of cost shifting - without changing the status quo of the organization's units involved in such cost shifts.

This study adopts organization learning concepts (Hamilton and Tee, 2010) through an employer sponsored training program (Ni and Sun, 2009) and develops a theoretical utility sector organization approach capturing cost shifting and possible solutions. This hypothetical utility sector organization operates within budgetary constraints, and offers products through two opposing units - a monopoly unit, and a competitive unit. Here, cost shifting is assumed as offering short-term solutions (Gal-Or 1993, Cavalluzzo et al. 1998) but also presents associated longer-term consequences such as productivity improvements and/or wage gains (Bartel 2000).

In monopoly units, cost shifting initially increases costs of the recipient unit (see for example, Gal-Or 1993, Cavalluzzo et al. 1998, Holladay and Quiñones 2003, Keith and Frese 2008, Aguinis and Kraiger 2009), but this recipient monopoly unit may receive senior management direction if its budget threshold is exceeded and resultant cost shift outcomes deliver losses over the longer-term. Production and operations management literature suggests senior management initiatives such as training and development, research and development, and/or process improvement are possible pathways to reduce the recipient unit's cost shifted problems (Holladay and Quiñones 2003, Keith and Frese 2008, Aguinis and Kraiger 2009).

Utilities are generally government service organizations (Breautigan and Panzer 1990, Gal-Or 1993, Cavalluzzo et al. 1998). Hence, we adopt training as a preferred pure-services approach. Like others, we use overhead cost as a surrogate for efficiency and productivity within this utility monopoly unit (Gal-Or 1993, Cavalluzzo et al. 1998), and adopt a utility strategic-planning period of five years (Langfield-Smith 2011). We map our investment in employee training against a projected increase in employee productivity, offset against the added overhead costs of the trainer (see Bartel 2000 for a review). The total costs of the monopoly and competitive unit at 'pre cost shifting' represent the 'status quo' baseline (in terms of cost efficiency, productivity, and target cost). Next we model against this baseline and deliver our assessment.

\section{LITERATURE REVIEW}

Many regulatory economics-based studies tackle cost shifting (Breautigan and Panzer 1990, EBRI 1993, McGowan and Vendrzyk 2002). Accounting literature also assesses cost shifting (EBRI 1993, Cavalluzzo et al. 1998, McGowan and Vendrzyk 2002) with these costs usually defined as overhead costs (Cavalluzzo et al. 1998, McGowan and Vendrzyk 2002). Such costs usually arise from senior management considerations - where overheads are imposed (or allocated) as extras to the recipient business unit (Breautigan and Panzer 1990, EBRI 1993, Cavalluzzo et al. 1998, McGowan and Vendrzyk 2002). Such costs are shifted from one business unit to another to provide short-term relief for one unit at the expense of others (EBRI 1993, Cavalluzzo et al. 1998, McGowan and Vendrzyk 2002).

\subsection{Cost shifting: Strategy and profitability considerations}

In government defense units costs shift from external commercial units to monopoly internal units including production planning (Breautigan and Panzer 1990), improvements to the-bottom-line (Breautigan and Panzer 1990, McGowan and Vendrzyk 2002), compliance 
with regulations (Cavalluzzo et al. 1998), and the maximization of cost reimbursements from government (Braeutigam and Panzar 1989, Breautigan and Panzer 1990, Brennan 1990, McGowan and Vendrzyk 2002). Cost shifting is also driven by desires to increase profits (Rogerson 1992), or to minimize budget allocated costs (Breautigan and Panzer 1990, Brennan 1990), or to improve a strategic market (Gal-Or 1993, Cavalluzzo et al. 1998).

Literature considers reasons and motivations for cost shifting. Sweeny (1982), and Brennan (1990) note utilities deliberately shift overheads from commercial units into their regulated units. This has impact on their production and/or output decisions. Rogerson (1992) also observes overhead cost shifting in contracts between competitive organizations and solesourcing government units. Thomas and Tung (1992) show maximization of pension fund returns by defence contractors arises when commercial arrangements are moved into government units. Cavalluzzo et al. (1998) observes that in response to changes to the Monetary Control Act, costs shifted within two operating departments (from a competitive department and a regulated monopoly department) within the US Federal Reserve Bank. They conclude cost shifting help improve profitability within the competitive unit, allowing it to compete with similar services provided by external operations. They contend that this cost shifting did not change the status-quo of the monopoly segment.

Cost shifting in healthcare typically arises with changes in policies on cost reimbursement or budgetary allocation. Carey (1994) and Eldenberg and Kallapur (1997) suggest changes in government reimbursement policies led US hospitals to shift allocated overheads from fixed reimbursement in-patient departments to flexible out-patient departments - where reimbursement depend on costs. Similarly, Soderstorm $(1990,1993)$ note in response to Medicare reimbursement changes hospitals shifted costs from cost-plus to fixed-fee diagnosis areas where higher reimbursement fees applied. Blanchard (1986) and Eldenberg and Soderstrom (1996) add that hospitals manipulate their budgeting rules to relieve revenue constraints such as cost-based reimbursement. Other health-care studies such as EBRI (1993), find hospitals shift costs between payers - with some payer-groups paying more than others.

In the regulatory sector, however, Arrow (1995) found no evidence that regional telecommunications providers shift costs from unregulated to regulated businesses or business units. Gal-Or (1993) offers a model where two firms sell products in two different niche markets - one in an oligopoly, and the other in a competitive market. She argues a firm can deliberately reallocate overhead costs from its oligopoly to its competitive units, and vice-versa. This improves either unit's profitability (or its strategic position), and causes the competitor to shrink production levels and/or to suffer losses. In other public sector utility organizations cost shifting and productivity improvements sometimes lack clarity of direction and have encounter-competing internal cultures that can extend across opposing internal business units (Halachmi and Bovaird 1997, Niehaves et al. 2012).

Hence, cost shifting may be used as a strategy to minimize cost and/or to improve profitability in selected business units within a service organization.

The above approaches may be management driven, policy-based, or in response to regulatory demands. These shifts in costs are treated as short-term solutions, and are seldom considered over extended ( 5 year) time periods.

\subsection{Cost shifting: Enlisting training of employee}

Workplace training improves individual, team, and organizational effectiveness through systematic developments in job-related capabilities (Goldstein 1993). These training activities result in the acquisition of new personal knowledge and in skills growth. Aguinis and Kraiger (2009) divide training into a five-zone continuum of: needs-assessment, design; 
delivery; evaluation; and transfer-of-knowledge. Pure training resides at the lower end of this continuum with highest productivity increases arising at the upper training extremity.

Needs assessment identifies skills gaps and defines suitable training programs (Blanchard 1986, Fowlkes et al. 2000, Baranzini et al. 2001). Although complementary, different training approaches/methods are independent, but each shares the objective of increasing productivity (Aguinis and Kraiger 2009) - including improved employee productivity (Heimbeck et al. 2003, Holladay and Quiñones 2003, Linou 2004, Keith and Frese 2008, Aguinis and Kraiger 2009) through the collective acquisition of organizational knowledge and by added employee capabilities. Keith and Frese (2005, Keith and Frese 2008) and Aguinis and Kraiger (2009) state trainee meta-cognitive abilities can engage both training activities and knowledge acquisition. Here, learning materials can be imparted through: technology-driven instructions; remote training; and outcome-based training, but differing training methods best match certain types of trainees and their training environments.

As trainees improve their individual performances they add to the organisation's productivity increases, profitability, cost reductions and quality improvements (Aguinis and Kraiger 2009). Indirect organizational benefits such as: reduction in employee turnover, enhancement of organizational reputation, and development of social capital can also occur. Although, Aguinis and Kraiger (2009) also contribute to the changing personal and organizational productivities. This study narrows the training focus to cost reduction considerations - ones that impinge on organizational productivity increases.

\subsection{Cost shifting: Training and cost reduction considerations}

Changes in productivity created by training 'scale effects' hold associations with cost and productivity (Dutton and Thomas 1984, Bartel 1994, Grifell-Tatjé and Lovell 1999, Aghazadeh 2007, Almeida and Carneiro 2009). Cost shifting also drives staff productivity improvements and reduces costs over time (Terziovski and Sohal 2000). Here, new technologies (Theodorakopoulos et al. 2012), services technological systems improvements (Badescu and Garcés-Ayerbe 2009), research and development (Coccia 2012), and employee training/skills building (Terziovski and Sohal 2000, Ni and Sun 2009) can reduce costs, improve competitiveness, and build user perceptions regarding the services provided ( $\mathrm{Hu}$ and Hsu 2008, Mansury and Love 2008, Hsieh et al. 2012). Literature adds this improvement is not always sustainable, but both internal efficiencies and effectiveness improvements often arise (Hu and Hsu 2008). For example, Shin and Park (2010) report a Korean ICT industry delivered $75 \%$ internal knowledge improvements and $150 \%$ cost savings, and in addition technological advances improve return on investment over time (Bartel 2000; (Bunduchi et al. 2011).

Collating manufacturing cost reduction literature Dutton and Thomas (1984) state: '...because of increase in production rate total unit cost reductions can be attributed not only to absorption of indivisible fixed costs but also to economies from Horndal-type adaptations that are facilitated by rate increases'. Darr et al. (1995) support this scale effect showing such knowledge and/or product-mix cost reductions emerged from added learning-by-doing or through increased experiential learning over time.

Darr et al. (1995) observe knowledge transfer within franchises contributed to production increases and cost reductions, but these savings in manufacturing average unit costs and in knowledge advantages diminish over time. Sinclair et al. (2000) studied one thousand chemical manufacturers showing process innovation and research and development additions also deliver cost reductions. Here, manufacturing scale effect learning is both 
technology-centred and employee centred (Santamaría et al. 2012), but learning-by-doing effects follow, and time lag behind: innovation, research and development, and procedural contributions to cost reductions (Ignatius et al. 2012).

In contrast, a service organisation's scale effects relate strongly to learning-by-doing productivity increases (Hamilton and Tee, 2010). Employees often directly drive change, learn more by 'doing', and strongly 'own' further productivity changes, and associated cost reductions. These employee gains are often retained longer (Darr et al. 1995).

Efficiency gains through knowledge transfer across service organisational networks can reduce organizational costs. Lapré et al. (2000) argue knowledge base sciences offer productivity increases through employees who glean/apply such ideas to generate productivity gains. When top management intervenes to drive productivity changes, significant efficiencies and productivity improvements can be exposed (Finch, 2008), yet Lapré et al. (2000) failed to find significant productivity improvements from acquired knowledge across three production plants. Hence, managerial variables may not be deeply embedded across all productivity improvement initiatives.

Cost reduction measured as time spent on experimentation, experience, and production volume (Sinclair et al. 2000) in a labour intensive chemical plant, reduces costs as production volumes increase (Liberman (1984 ). Argote et al. (1990) adds average costs do not change with high labour turnover, but others (Huselid 1995) argue high labour turnover disrupts both production and average costs in firms such as in shipyards.

Sinclair et al. (2000) observes learning from continual production across units owned by the same firm (Darr et al. 1995), and across firms in close proximity (Jarmin, (1994b), also aids cost reductions.

Several manufacturing studies note organizational cost reduction is temporal (Darr et al. 1995), but not-for-profit and government organizations may adopt further ways to reduce costs (Woodward et al. 1999, Kim 2005).

As cost shifting drivers, and management imperative drivers differ over time, we deploy a hypothetical government-sector service organization applying training to explore the plausibility of cost reduction opportunities. We present scenarios where managers face different dilemmas around cost allocations (Gal-Or 1993), and we consider alternative solutions to the juxtaposition problem of cost shifting, cost reduction, and productivity improvement over the longer-term.

\section{SHORT TERM COST ALLOCATION AND COST SHIFTING DILEMMA}

Our hypothetical government-sector service organization is semi-profitable - with a monopoly unit, and a competitive unit, as its two operating arms. Its output and employee structure are considered fairly stable, and predictable. Our hypothetical service organization generates its income from grants, and from the commercial sales of services to its local communities. In any year, its main objective is to balance its budget within the monopoly unit, and to generate a surplus in the competitive unit.

Our hypothetical government-sector service organization's total costs comprise the direct costs of the units and shared overheads allocated by senior management. The performance of its monopoly unit reflects the compensation structure of the employees, and the work environment requirements. The total costs of these monopoly and competitive units drive their outputs - which are crucial in the auditing of ongoing government funding, and support their survival within the competitive local economy (cf. Breautigan and Panzer 1990, 
Brennan 1990, Rogerson 1992). The control of costs also influences future monopoly grant funding and budgeting of its outside competitive services revenue streams.

In a year, total costs $\left[T C_{c}\right]$ of the competitive services unit comprise direct costs $\left[\mathrm{dc}_{\mathrm{c}}\right]$ and a portion of allocated overheads - termed alpha $[\alpha]$. Its operating environment is defined by the services provided, and by its geographical (or operational) areas of influence. It is profit driven, with prices set against its competitors.

The relationship between total cost $\left[T C_{c}\right]$ and the average unit cost $\left[A C_{c}\right]$ for this competitive services unit is show as equations 1 and 2 .

$$
\begin{aligned}
& T C_{c}=d c_{c}+\alpha \\
& A C_{c}=\frac{d c_{c}+\alpha}{q_{c}}
\end{aligned}
$$

where $\mathrm{q}_{\mathrm{c}}$ is the estimated output quantity of the competitive unit, $\mathrm{dc}_{\mathrm{c}}$ is all direct costs within the competitive unit measured as all fixed and variable production costs, and $\alpha \varepsilon[0,1]$ is the allocated portionof the imposed common support costs of the organization.

Total costs of the monopoly services unit $\left[T C_{m}\right]$ again comprise the direct costs $\left[\mathrm{dc}_{\mathrm{m}}\right]$ of the department, plus the unallocated portion of overheads from the total overheads of the services organization $[1-\alpha]$. The monopoly unit remains less concerned about spending levels (as it is protected by government legislation and funding grants). The monopoly services unit is not sufficiently lucrative to attract private sector competitors. Nonetheless, its stakeholders evaluate these budget levels. Equations 3 and 4 describe the monopoly services unit's total costs $\left[\mathrm{TC}_{\mathrm{m}}\right]$, and its average unit cost $\left[\mathrm{AC}_{\mathrm{m}}\right]$.

$$
\begin{aligned}
& T C_{m}=d c_{m}+(1-\alpha) \\
& A C_{m}=\frac{d c_{m}+(1-\alpha)}{q_{m}}
\end{aligned}
$$

Figure 1 presents the above starting-point cost allocations relationship, and Figure 2 shows the new short-term cost shifting allocations relationship.

\section{<insert figures 1 and 2 about here>}

Short-term outputs show production quantity at normal capacity utilization levels, with average unit costs of each unit inversely related to production quantity.

Under funding and government grant budget limitations, costs of each operational unit are typically under senior management scrutiny. If the monopoly unit's budget exceeds its government legislated limit, the monopoly unit then becomes like a competitive unit, and is subject to rationalisation considerations.

The monopoly and competitive units have no interdependencies but their overhead costs are complimentary. Where the competitive unit is under intense pressure to reduce the prices of its services, it advises senior management its overheads allocation against those of 
the monopoly unit needs adjustment - possibly seeking monopoly unit employee retrenchments as a way to deliver overhead costs (salaries and on-costs) savings.

Where senior management recognises significant inefficiencies exist within the monopoly unit it may transfer some poorly allocated overhead costs from the competitive unit to the monopoly unit. Hence the competitive unit remains successfully in the marketplace, and the monopoly unit with added overhead costs must become more efficient possibly through enhanced training to generate added productivity (and not through job losses).

Equations 5 and 6 show the new total costs and the new average costs of the monopoly unit.

$$
\begin{aligned}
& T C_{m}=d c_{m}+(1-\alpha)+\tau \\
& A C_{m}=\frac{d c_{m}+(1-\alpha)+\tau}{q_{m}}
\end{aligned}
$$

where $\tau$ is the added costs to the monopoly unit

In the monopoly unit as the production maximizes and approaches to the maximum threshold of the relevant range, the average unit costs reduce to minimum. This new cost sharing arrangement solves the competitive unit's problem, but it challenges the monopoly unit to reduce costs within 5 years. This long-term approach is discussed in the following section.

\section{LONG-TERM COST ALLOCATION APPROACH}

Based on modelling, we envisage longer term solutions are best for government-sector service organizations. Our approach differs from past approaches used in regulatory economics (Breautigan and Panzer 1990, Brennan 1990, Gal-Or 1993) and is based on the following assumptions.

a. Cost functions are linear within the relevant range

b. Demand function is known with certainty for the sustained period of time (or during the training period)

c. Training costs are upfront lump sum payments to the training provider

d. Employee turnover during training exerts no significant influence on total productivity within the monopoly unit

e. The size of the organization and its budgets for future years are constant during the training period

f. Employees have opportunities to practice their acquired knowledge on their daily tasks, and all employees in the monopoly unit have shared understanding that their training is rewarding to them (for tenure and/or career progression), and to the monopoly unit.

Where senior management offers external consultancy assistance to address the monopoly unit's productivity issues, and a production training approach (with resultant skills and efficiency improvements) is provided to reduce extra-overhead costs over time, then training 
cost $[\gamma]$ is assigned to the monopoly unit's overhead cost as it accrues the benefits from this approach. Figure 3 depicts this scenario.

\section{$<$ Insert Figure 3 about here $>$}

Figure 3 is senior management's initial step in solving the monopoly unit's increased overhead costs over the long-term. This 'ramp-up' process captures the time from investment in training and R\&D through to the time when the employees have learned to apply their newly acquired skills (Dutton and Thomas 1984, Adler and Clark 1991, Sinclair et al. 2000, Tether and Metcalfe 2003). Initially the monopoly unit's total costs and average unit costs increase due to investment in training and $R \& D$, whilst the employee training recipients initially remain at past productive levels.

The long-term cost equation 7 is selected to match normal 5 year strategic planning and 'rolling budget' cycles (Finch, 2008).

$$
\sum_{t=1}^{5}\left\{\left(d c_{m}+(1-\alpha)+\tau\right)+\gamma\right\}
$$

The monopoly unit's total training cost initially for the strategic planning period (five year budget period) $[\gamma]$ gradually falls over time as employees apply their new productivityrelated skills (Adler and Clark 1991, Sinclair et al. 2000, Tether and Metcalfe 2003). As management implements consultant-driven productivity enhancement processes within the 5 year time span initial increased costs are fully offset by an improvements gain of eta $[\vartheta]$ as per equation 8 .

$$
\sum_{t=1}^{5}\left\{\left(d c_{m}+(1-\alpha)+\tau\right)+\gamma\right\}-\vartheta
$$

Here, we assume employee knowledge and skills are not degraded through productivity improvements over time - typically generated via technological improvements within the production process (and including waste reduction), along with enhanced management techniques (Finch, 2008).

Continuous knowledge transfer across senior management and employees drives additional challenges in performing assigned tasks (Adler et al., 2010). This phase of abilities is labelled [ $\mathrm{Lim}_{q_{m} \rightarrow \max }$ ]. Here, we assume tasks are performed manually/mechanically (Adler and Clark 1991), with technology-aided devices, and with cloud-engaging intelligent software driven processes (Demarest \& Wang, 2010; Lyer, 2012).

Equation 9 shows the monopoly unit's final target as it considers its original equation 3 cost $[\mathrm{dc}+(1-\alpha)]$, and then aims to reduce its final overhead cost below the original level $[1-\alpha]$. 


$$
\sum_{t=1}^{5}[\{(\tau)+\gamma\}-\vartheta]=0
$$

Under these conditions the monopoly unit approaches maximum productivity [ $\left.\operatorname{Lim}_{q_{m} \rightarrow \max }\right]$, and its average unit cost approaches a minimum. This is shown through equation 10 .

$$
\operatorname{Lim}_{q_{m} \rightarrow \max } \frac{d c_{m}+(1-\alpha)+\tau+\gamma}{q_{m}}=\min
$$

Hence, the average unit cost reduces to a minimum, and the monopoly unit keeps its overhead costs at or below original level. Figure 4 highlights this final scenario as the downward arrow component, and if the minimum cost is $\left[\mathrm{TC}_{n}\right]$, it may lead to the beneficial inequality shown through Equation 11.

$$
\begin{aligned}
& \quad \sum_{t=1}^{5}\left(T C_{n}-T C_{n t}\right) \leq 0 \\
& <\text { Insert figure 4 about here > }
\end{aligned}
$$

Provided the utility sector's monopoly unit's long-term cost reduction objective is achieved via costs shifting and productivity enhancements, both a minimization of average unit costs, and a maximization of productivity are conjointly approached. Hence, targeted productivity training programs linked to long-term overhead reductions offer a better alternative to straight short-term cost shifting strategies.

Some suggest further managerial maneuverings such as staff reductions can further reduce costs but these may create degrees of employee demoralization (Argote et al. 1990, Adler and Clark 1991, Argote and Ingram 2000, Tether and Metcalfe 2003). Thus, to broaden the scope of the long-term cost shifting advantages presented herein, it may be wise to subject other productivity cost savings (ones not related to skills/technical training deliverance initiatives) to similar rigorous risk-return evaluations as those used in this study.

\subsection{IMPLICATIONS OF RESEARCH}

\subsection{Theoretical Implications}

We address productivity and cost reduction concerns in government-sector services/utility-sector organizations - especially those operating with shrinking revenue bases. We note short-term cost shifting offers little opportunities to raise performances. We assess employee training as a possible solution for productivity improvements and cost reduction and consider extended long-term time periods offer greater options.

Our mathematical approach is of use to academics and practitioners seeking to identify root causes of typical inefficiencies associated with utility sector cost shifting between government sector organizational units (Osborne and Gaebler 1992, Hood 1995). Our theoretical, causal-chain approach adopts productivity-related organizational learning using employee training to demonstrate employee capability enhancements (such as learning, skills and knowledge creation) and the subsequent deliverance of productivity improvements (shown as cost reductions). This modeled approach is expandable by including other 
productivity change generators such as datamined service gateways improvements into this mathematical model.

\subsection{Practical Implications}

In Australia, public sector organizations can only charge customers for their services at or below government-regulated limits. Hence a monopoly unit incurring added shifted costs generates savings using alternate means such as utilizing training to increase employee capabilities and capacities (see for example, Braeutigam and Panzar 1989, Brennan 1990). In contrast, the services of the unregulated competitive unit being outside these regulatory price caps becomes subject to competitive marketplace pricing. Researchers are encouraged to deliver optional commercial approaches by benchmarking and comparing such cost-related areas under both short-term and long-term timeframes.

Our model shows over the long-term employee training is one option that potentially lowers the cost of service, and that two internal business units can strategically cost-shift generating added servicing capabilities for the competitive unit, and building monopoly unit services efficiencies not possible under short-term approaches. Thus researchers are encouraged to approach cost shifting as a long-term approach, and to investigate cost shifting potentials as a means to enhance a government utility-sector's net competitive and monopoly unit cost positions.

Similarly, private organizations can be long-term tested using cost shifts between business units. Here, additional internal monopoly unit variables such as (1) computer-based intelligent suites; (2) workload/task efficiency and performance audits; (3) individual inefficiencies reductions; (4) strategic management long-term survival considerations; and (5) budgetary item analysis (Rogerson, 1992; Gal-Or, 1993; Cavalluzzo et al., 1998) can be similarly modeled to seek profit maximization and costs minimization. Considering private organization scaling business process reengineering, economies of scale, and wastage reduction (Bartel 1994, Berman and West 1998) can also be investigated.

\section{FUTURE RESEARCH IMPLICATIONS}

\subsection{Measurement Aspects}

Future research into other cost reduction effects such as: no-cost systems refinements, combined environmental and internal knowledge applications, and dynamic innovation effectors in time may offer short-term and long-term cost reducers, with various mixes applying to government sector units and/or to private (competitive) servicing environments.

\subsection{Theoretical Aspects}

Our two-pronged cause-and-effect approach exposes a base level measurement approach into long-term cost shifting. There is considerable scope for researchers to investigate, resolve and so reduce the assumptions applied herein.

\subsection{Management Aspects}

Managers can now recognize some effects created by their short-term attempts to shift overhead costs, and can develop strategies to minimize these changes. This Australian government utility-sector approach shows managers allocating some training resources to the business unit incurring the cost shifting penalties but this unit can generate added growth benefits within its areas of responsibility. 


\section{CONCLUSION}

Cost shifting strategy in service organizations creates different challenges to coexisting internal business units when each competes for scarce resources. Within regulatory and legal constraints, cost shifting between business units instigates concomitant changes to each unit's profitability/budget-surpluses. For internal competing units, this strategy has shortcomings. Through management sponsored training programs such as employee learning and productivity improvements long-term approaches are proposed in place of management's normal short-term cost shifting approaches.

Our mathematical approach addresses such longer-term effects of cost shifting. We model a semi-profitable government-sector service organization utilizing its two operating arms (monopoly unit, and competitive unit) both performing predictably in terms of output and employee engagement, and within a fairly stable/predictable environment. This long term (5 year) government utility-sector service organization approach shifts overhead costs to the monopoly unit, and improves the competitive unit's profitability. The monopoly unit then uses employee training as a long-term strategic pathway to find efficiencies and productivity overhead cost reductions. Compared to alternate short-term cost shifting, our long-term approaches focus on increasing monopoly unit's productivity outcomes whilst growing the competitive unit's marketspace - thereby adding value to both units.

We also outline current and future research opportunities that may be included in an expanded version of our model - thereby delivering additional cost reductions and further offsetting the effects of cost shifting.

\section{LIMITATIONS}

Throughout this long-term (5 years) two-pronged study, cost changes are assumed linear and the organization is operating under budgetary constraints. In addition, after cost shifting, and based on literature, employee training over-time is assumed to exert positive yet different capacity and capability effects on both the competitive and the monopoly units.

\section{REFERENCES}

Adler, P.S. and Clark, K.B., 1991. Behind the Learning Curve: A Sketch of the Learning Process. Management Science, 37, 267-281.

Aghazadeh, S.M., 2007. Re-examining the training side of productivity improvement: evidence from service sector. International Journal of Productivity and Performance Management, 56, 744-757.

Aguinis, H. and Kraiger, K., 2009. Benefits of training and development for individuals, teams, organizations, and society. Annual Review of Psychology, 451-474.

Almeida, R. and Carneiro, P., 2009. The return to firm investments in human capital. Labour Economics, 16, 97-106.

Argote, L., Beckman, L. and Epple, D., 1990. The Persistence and Transfer of Learning in Industrial Settings. Management Science, 36, 140-154

Argote, L. and Ingram, P., 2000. Knowledge transfer: A basis for competitive advantage in firms. Organizational behavior and human decision processes, 82, 150-169.

Arrow, K.J., D. W. Carltons, and H. S. Sider. , 1995. The competitive effects of line of business restrictions in Telecommunications. Managerial and Decision Economics, 301-321.

Badescu, M. and Garcés-Ayerbe, C., 2009. The impact of information technologies on firm productivity: Empirical evidence from Spain. Technovation, 29, 122-129. 
Baranzini, D., Bacchi, M. and Cacciabue, P., 2001. A tool for evaluation and identification of training needs in aircraft maintenance teams. Human Factors and Aerospace Safety, 1, 167-193.

Bartel, A.P., 1994. Productivity gains from the implementation of employee training programs. Industrial Relations: A Journal of Economy and Society, 33, 411-425.

Bartel, A.P., 2000. Measuring the employer's return on investments in training: Evidence from the literature. Industrial Relations: A Journal of Economy and Society, 39, $502-$ 524.

Berman, E.M. and West, J.P., 1998. Productivity enhancement efforts in public and nonprofit organisations. Public Productivity \& Management Review, 207-219.

Blanchard, G.A., Chow, C. W., \& Noreen, E., 1986. Information Asymmetry, Incentive Schemes, and Information Biasing: The Case of Hospital Budgeting under Rate Regulation. The Accounting Review, 61, 1-15.

Braeutigam, R.R. and Panzar, J.C., 1989. Diversification incentives under" price-based" and" cost-based" regulation. The RAND Journal of Economics, 373-391.

Breautigan, R. and Panzer, J., 1990. Diversification incentives under 'Price-Based' and 'Cost Based' regulation. Rand Journal of Economics, 373-391.

Brennan, T., 1990. Cross-Subsidization and cost misallocation by regulated monopolies. Journal of Regulatory Economics, 37-52.

Bunduchi, R., Weisshaar, C. and Smart, A.U., 2011. Mapping the benefits and costs associated with process innovation: The case of RFID adoption. Technovation, 31, 505-521.

Carey, K., 1994. Cost allocation patterns between hospital inpatient and outpatient departments. Health Services Research, 275-292.

Cavalluzzo, K.S., Ittner, C.D. and Larcker, D.F., 1998. Competition, efficiency, and cost allocation in government agencies: Evidence on the Federal Reserve System. Journal of Accounting Research, 36, 1-32.

Coccia, M., 2012. Political economy of R\&amp;D to support the modern competitiveness of nations and determinants of economic optimization and inertia. Technovation, 32, 370-379.

Darr, E.D., Argote, L. and Epple, D., 1995. Darr, E. D., Argote, L., \& Epple, D. (1995). The Acquisition, Transfer, and Depreciation of Knowledge in Service Organizations: Productivity in Franchises. Management Science (Focused Issue on Service Management), 41, 1750-1752.

Dutton, J.M. and Thomas, A., 1984. Treating Progress Functions as a Managerial Opportunity. The Academy of Management Review, 9, 235-247.

Ebri, 1993. Hospital pricing: Cost shifting and competition.

Eldenberg, I., And N. Soderstrom. , 1996. Accounting system management by hospitals operating in response to changes in Medicare reimbursement schemes. The Accounting Review, 71, 23-42.

Eldenberg, I. and Kallapur, S., 1997. Changes in hospital service mix and cost allocations in response to changes in Medicare reimbursement schemes. Journal of Accounting and Economics, 23, 31-51.

Fowlkes, J.E., Salas, E., Baker, D.P., Cannon-Bowers, J.A. and Stout, R.J., 2000. The utility of event-based knowledge elicitation. Human Factors: The Journal of the Human Factors and Ergonomics Society, 42, 24-35.

Gal-Or, E., 1993. Strategic cost allocation. The Journal of Industrial Economics, 387-402.

Goldstein, I.L., 1993. Training in organizations: Needs assessment, development, and evaluation: Thomson Brooks/Cole Publishing Co. 
Grifell-Tatjé, E. and Lovell, C.a.K., 1999. Profits and productivity. Management science, 1177-1193.

Halachmi, A. and Bovaird, T., 1997. Process reengineering in the public sector: Learning some private sector lessons. Technovation, 17, 227-235.

Heimbeck, D., Frese, M., Sonnentag, S. and Keith, N., 2003. Integrating errors into the training process: The function of error management instructions and the role of goal orientation. Personnel Psychology, 56, 333-361.

Holladay, C.L. and Quiñones, M.A., 2003. Practice Variability and Transfer of Training: The Role of Self-Efficacy Generality. Journal of Applied Psychology, 88, 1094-1103.

Hood, C., 1995. The "New Public Management" in the 1980s: variations on a theme. Accounting, organizations and society, 20, 93-109.

Hsieh, P.-F., Lee, C.-S. and Ho, J.C., 2012. Strategy and process of value creation and appropriation in service clusters. Technovation, 32, 430-439.

Hu, J.-L. and Hsu, Y.-H., 2008. The more interactive, the more innovative? A case study of South Korean cellular phone manufacturers. Technovation, 28, 75-87.

Huselid, M.A., 1995. The impact of human resource management practices on turnover, productivity, and corporate financial performance. Academy of management journal, 635-672.

Ignatius, J., Leen, J.Y.A., Ramayah, T., Kah Hin, C. and Jantan, M., 2012. The impact of technological learning on NPD outcomes: The moderating effect of project complexity. Technovation, 32, 452-463.

Jarmin, R.S., 1994b. Asymmetric learning in the U.S. manufacturing industries.

Keith, N. and Frese, M., 2005. Self-Regulation in Error Management Training: Emotion Control and Metacognition as Mediators of Performance Effects. Journal of Applied Psychology, 90, 677-691.

Keith, N. and Frese, M., 2008. Effectiveness of error management training: A meta-analysis. Journal of Applied Psychology, 93, 59-69.

Kim, S., 2005. Individual-level factors and organizational performance in government organizations. Journal of public administration research and theory, 15, 245-261.

Langfield-Smith, K., 2011. Management Accounting: Information for creating and managing value, 6th ed.: McGraw-Hill Higher Education.

Lapré, M.A., Mukherjee, A.S. and Van Wassenhove, L.N., 2000. Behind the learning curve: Linking learning activities to waste reduction. Management Science, 597-611.

Liberman, M.B., 1984 The learning curve and pricing in the chemical processing industries. Rand Journal of Economics, 213-228.

Linou, N., 2004. The effect of training systemic information on the retention of fault finding skills in manufacturing industries. Human Factors and Ergonomics in Manufacturing \& Service Industries, 14, 197-217.

Mansury, M.A. and Love, J.H., 2008. Innovation, productivity and growth in US business services: A firm-level analysis. Technovation, 28, 52-62.

Mcgowan, A.S. and Vendrzyk, V.P., 2002. The relation between cost shifting and segment profitability in the defense-contracting industry. Accounting Review, 949-969.

Ni, W. and Sun, H., 2009. The relationship among organisational learning, continuous improvement and performance improvement: An evolutionary perspective. Total Quality Management, 20, 1041-1054.

Niehaves, B., Plattfaut, R. and Becker, J., 2012. Business Process Governance: A Comparative Study of Germany and Japan. Business Process Management Journal, $18,8-8$. 
Osborne, D. and Gaebler, T., 1992. Reinventing government: How the entrepreneurial spirit is transforming the public sector; Reinventing government: How the entrepreneurial spirit is transforming the public sector: Addison-Wesley Publishing.

Rogerson, W.P., 1992. Overhead allocation and incentives for cost minimization in defense procurement. Accounting Review, 671-690.

Santamaría, L., Jesús Nieto, M. and Miles, I., 2012. Service innovation in manufacturing firms: Evidence from Spain. Technovation, 32, 144-155.

Sinclair, G., Klepper, S. and Cohen, W., 2000. What's Experience Got to Do With It? Sources of Cost Reduction in a Large Specialty Chemicals Producer. Management Science, 46, 28-45.

Soderstrom, N., 1990. Are reporting errors under PPS random or systematic? Inquiry., 234241.

Soderstrom, N.S., 1993. Hospital behavior under Medicare incentives. Journal of Accounting and Public Policy, 12, 155-185.

Sweeney, G., 1982. Welfare implications of fully distributed cost pricing applied to partially regulated firms. The Bell Journal of Economics, 525-533.

Terziovski, M. and Sohal, A., 2000. The adoption of continuous improvement and innovation strategies in Australian manufacturing firms. Technovation, 20, 539-550.

Tether, B.S. and Metcalfe, J.S., 2003. Horndal at Heathrow? Capacity creation through co operation and system evolution. Industrial and Corporate Change, 12, 437-476.

Theodorakopoulos, N., Sánchez Preciado, D.J. and Bennett, D., 2012. Transferring technology from university to rural industry within a developing economy context: The case for nurturing communities of practice. Technovation.

Thomas, J.K. and Tung, S., 1992. Cost manipulation incentives under cost reimbursement: Pension costs for defense contracts. Accounting Review, 691-711.

Woodward, C.A., Shannon, H.S., Cunningham, C., Mcintosh, J., Lendrum, B., Rosenbloom, D. and Brown, J., 1999. The impact of re-engineering and other cost reduction strategies on the staff of a large teaching hospital: a longitudinal study. Medical Care, $37,556$. 


\section{APPENDIX ITEMS}

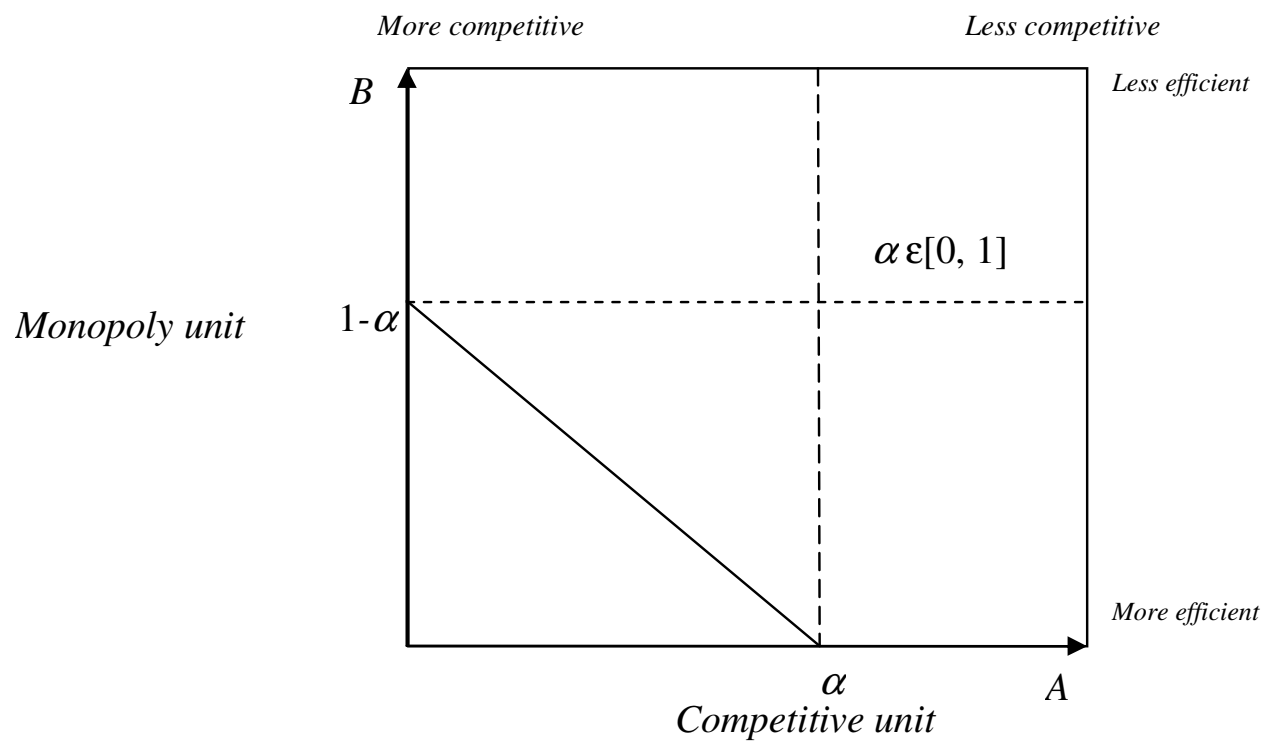

Figure 1: Relationship between overhead costs, competitiveness, and efficiency.

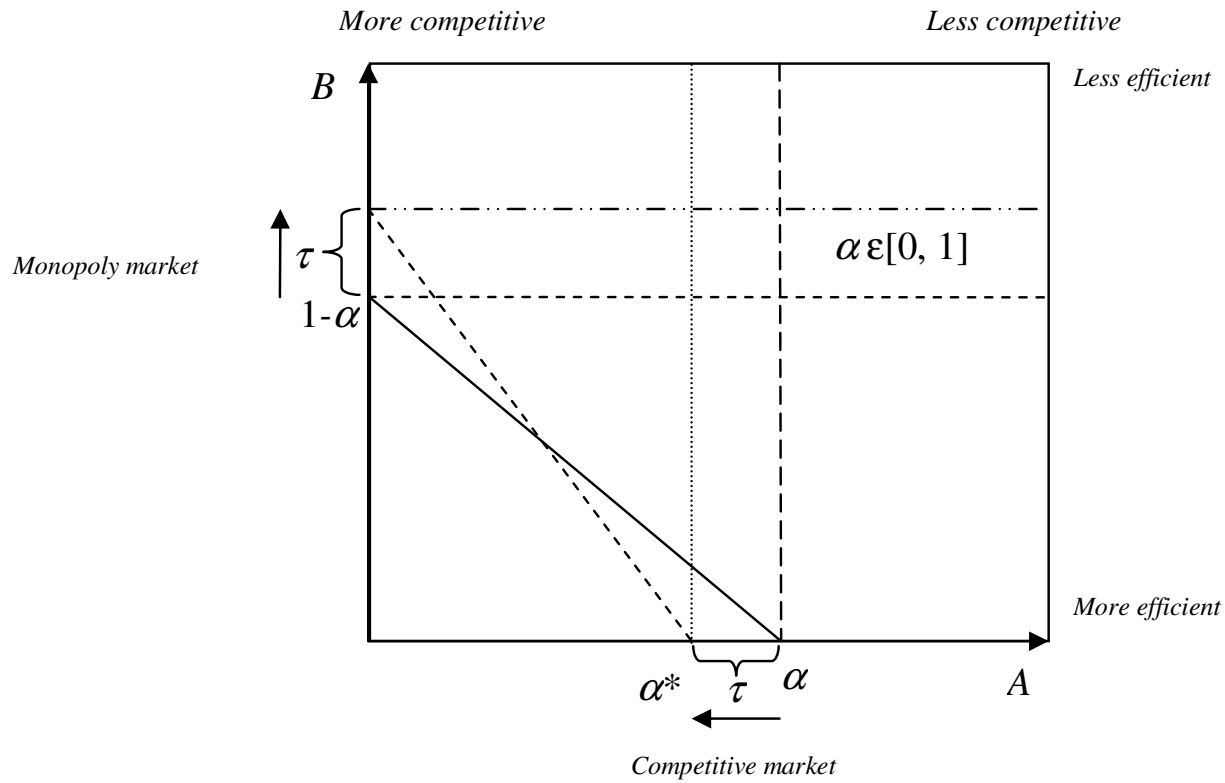

Figure 2: Cost shifting in the short term 


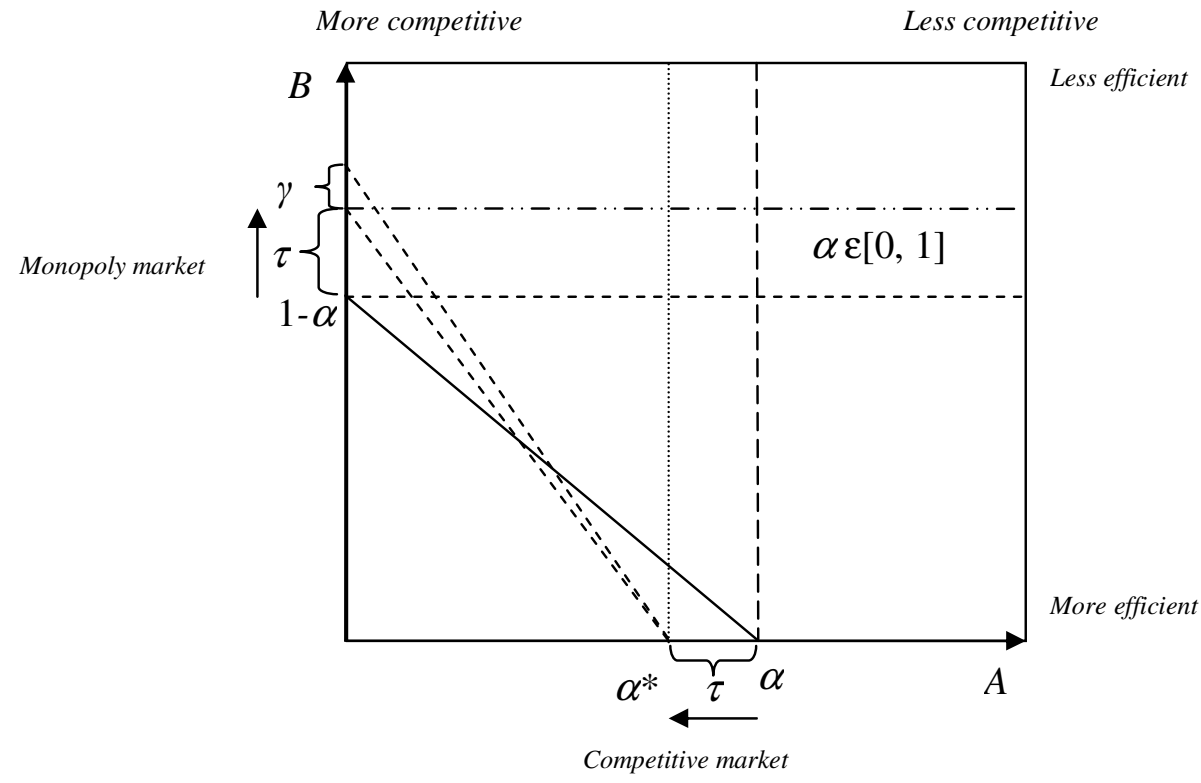

Figure 3: Cost reduction process in the longer term

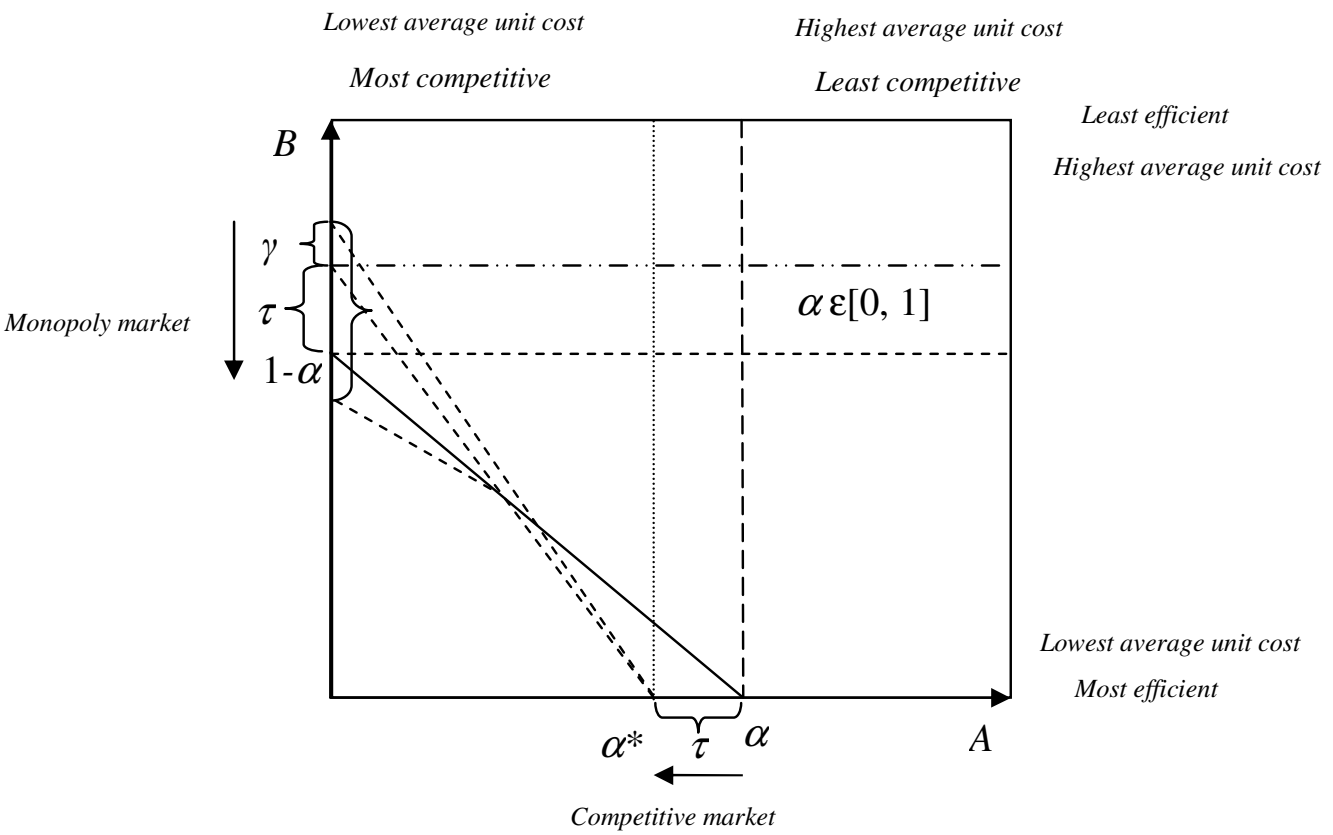

Figure 4: Target cost reduction after training and development activities 